\title{
A role for DNA supercoiling in the regulation of the cytochrome bd oxidase of Escherichia coli
}

\author{
Keren J. Bebbington and Huw D. Williams \\ Author for correspondence: Huw D. Williams. Tel: +44207594 5383. Fax: + 442075842056. \\ e-mail: h.d.williams@ic.ac.uk
}

Department of Biology, Imperial College of Science, Technology and Medicine, Imperial College Road, London SW7 2AZ, UK
The cydAB operon of Escherichia coli encodes cytochrome bd, a terminal oxidase in the aerobic respiratory chain. The high oxygen affinity of this oxidase explains its increased synthesis under low-oxygen conditions.

Expression of the $c y d A B$ operon is controlled by the ArcA/ArcB two-component system and the oxygen-sensing transcriptional regulator Fnr. However, cydAB expression is still induced upon entry into stationary phase or following a shift to anaerobic conditions in a mutant deleted for arcA and fnr [Cotter, P. A. \& Gunsalus, R. P. (1992), FEMS Microbiol Lett 91, 31-36]. Indeed, such a mutant contains $60 \%$ of the wild-type levels of spectrally detectable cytochrome bd. A possible mechanism to account for this regulation is that changes in negative supercoiling, which occur during a shift to low-oxygen or anaerobic conditions, may contribute to the regulation of the $c y d A B$ operon. This paper reports several lines of evidence in support of this idea. Firstly, the expression of cydAB, and the final level of spectrally detectable cytochrome $b d$, is sensitive to inhibitors of DNA gyrase, the enzyme responsible for introducing negative supercoils into DNA. Both nalidixic acid and novobiocin reduce cydA-lacZ expression in a concentration-dependent manner. Secondly, in a gyrA mutant, defective in DNA gyrase activity, expression of $c y d A B$ is reduced to a basal level that is no longer sensitive to the oxygen status. Both gyrase inhibitors and the gyrA mutation reduce cydAB expression in a strain deleted for arcA and $f(n r$, indicating that their effects are not mediated indirectly through ArcA or Fnr, but rather that they are likely to be direct effects on cydAB expression. In conclusion, the authors have shown that changes in DNA supercoiling play a role in the induction of $\mathrm{CydAB}$ expression and may provide a general way of increasing cytochrome bd levels in the cell in response to environmental stress.

Keywords: $\operatorname{arcA}, f n r$, oxygen, respiration, DNA gyrase

\section{INTRODUCTION}

The branched aerobic respiratory chain of Escherichia coli has two well-characterized terminal oxidases, cytochrome bo' (or $b_{3}$ ) and cytochrome bd (Poole et al., 1994; Poole \& Ingledew, 1987; Gennis \& Stewart, 1996). A third terminal oxidase encoded by the $c b d A B$ operon is called cytochrome $b d$ II, based on its high degree of homology to cytochrome $b d$, although its function is poorly understood (Dassa et al., 1991; Atlung \& Brøndsted, 1994; Sturr et al., 1996; Gennis \& Stewart, 1996). Cytochrome $b o^{\prime}$ and cytochrome $b d$ differ in their structural and functional properties and these differences have been invoked to explain why cytochrome $b o^{\prime}$ is favoured at high and cytochrome $b d$ at low oxygen concentrations (Gennis \& Stewart, 1996).
Cytochrome bo' belongs to the haem-copper oxidase superfamily (García-Horsman et al., 1994). It has a moderate affinity for $\mathrm{O}_{2}\left(K_{\mathrm{m}} \sim 0 \cdot 2 \mu \mathrm{M}\right)$ and it is an energetically efficient oxidase, as in addition to functioning in a redox loop it also acts as an electrogenic proton-pump (Gennis \& Stewart, 1996). Cytochrome $b d$ is encoded by the $c y d A B$ operon (Green et al., 1988) and it has no homology to members of the haem-copper oxidase superfamily. The enzyme is a heterodimer of two integral membrane polypeptides, subunit I (CydA, $58 \mathrm{kDa})$ and subunit II (CydB, $43 \mathrm{kDa}$; Miller \& Gennis, 1983). Subunit I contains the haem $b_{558}$ and it is probably the site of quinol oxidation (Lorence et al., 1987). The oxidase has two further haems, haem $b_{595}$ and haem $d$, which both bind exogenous ligands. The catalytic site, where oxygen is reduced to water, is thought to be a 
haem $d$-haem $b_{595}$ binuclear centre analogous to the haem- $\mathrm{Cu}_{\mathrm{B}}$ binuclear centre of the haem-copper oxidases (Poole et al., 1983; Rothery \& Ingledew, 1989; D'Mello et al., 1996; Hill et al., 1993), although some data contradict this idea (Junemann, 1997). In E. coli the expression of the cytochrome $b d$ complex increases at low oxygen tension (Rice \& Hempfling, 1978; Cotter et al., 1990; Iuchi et al., 1990) and the oxidase has a very high affinity for $\mathrm{O}_{2}\left(K_{\mathrm{m}}=3-5 \mathrm{nM}\right.$, D'Mello et al., 1996). It is energetically less efficient than cytochrome $b o^{\prime}$ as it does not function as a proton pump and it is relatively insensitive to inhibition by the classical cytochrome oxidase inhibitor KCN (Rice \& Hempfling, 1978; Pudek \& Bragg, 1974).

There is clear evidence for the role of the ArcA/ArcB two-component regulatory system and the oxygensensing transcription factor Fnr in the control of the cydAB operon (Lynch \& Lin, 1996; Cotter et al., 1990, 1997; Iuchi et al., 1990, Cotter \& Gunsalus, 1992). Two $c y d A B$ promoters have been identified by primer extension and both ArcA and Fnr regulate the transcription from the P1 promoter in response to anaerobiosis, with ArcA activating and Fnr repressing transcription under low-oxygen conditions (Cotter et al., 1997). However, more recent evidence makes it likely that Fnr exerts its effect indirectly by both increasing the ArcA levels in anaerobic cells and increasing the ArcA-P/ArcA ratio. However, numerous reports on the regulation of $c y d A B$ in a $\Delta \operatorname{arc} A \Delta f n r$ background indicate that the $c y d A B$ operon is still upregulated upon oxygen limitation, to a similar two- to fivefold degree as found in the wild-type strain, even though the absolute levels of transcription are lower in these mutants (Cotter et al., 1990, 1997; Iuchi et al., 1990; Cotter \& Gunsalus, 1992). This suggests that in addition to ArcA/ArcB and Fnr there are undiscovered factors that both sense the availability of oxygen and upregulate $c y d A B$ expression when oxygen is limited. Extensive studies on the regulation of oxygen-controlled genes in E. coli have not identified another transcriptional regulator involved in this process. However, one possibility is that a change in DNA structure or topology at the $c y d A B$ promoter could enhance the productive interaction of the RNA polymerase. Since the onset of anaerobiosis coincides with an increase in negative DNA supercoiling (Dorman et al., 1988), and cytochrome $b d$ expression is known to be induced maximally under low $\mathrm{O}_{2}$ conditions, we hypothesized that changes in DNA supercoiling may regulate cytochrome $b d$. The aim of this work was to test this hypothesis.

\section{METHODS}

Bacterial strains, media and growth conditions. The E. coli K12 strains used in this work are listed in Table 1 . Bacteria were routinely grown in $\mathrm{LB}$ medium, while $\mathrm{TB}$ was used for phage propagation (Silhavy et al., 1984). Minimal Medium A (MMA) (Miller, 1972) contained either DL-lactate $(0 \cdot 2 \%, \mathrm{w} / \mathrm{v})$ or glucose $(0.6 \%, \mathrm{w} / \mathrm{v})$ and was supplemented with the following amino acids where appropriate: arginine $(0.9 \mathrm{mM})$, histidine $(4.4 \mathrm{mM})$, isoleucine $(4 \mathrm{mM})$, and phenylalanine, tryptophan and tyrosine (all $0.2 \mathrm{mM}$ ). Aerobic cultures were grown in
Erlenmeyer flasks containing one-fifth the flask volume of culture medium. Starter cultures were prepared by inoculating a single colony from a plate into $5 \mathrm{ml}$ of the appropriate growth medium in $25 \mathrm{ml}$ sterile Universal tubes and incubating overnight in an orbital shaker. These starter cultures were then diluted 50-fold to inoculate growth experiments. All cultures were grown at $37^{\circ} \mathrm{C}$ and shaken at 200 r.p.m. Anaerobic growth was achieved by filling a $25 \mathrm{ml}$ Universal tube with medium and incubating in an anaerobic jar (GasPak, Becton Dickinson). Growth was followed by measuring the increase in $\mathrm{OD}_{600} \mathrm{~nm}$ in a Shimadzu MPS-2000 spectrophotometer.

High-titre $\lambda$ lysates were prepared by induction of a strain carrying $\lambda$ GC101 (Georgiou et al., 1988) by growing it to early exponential phase and then adding mitomycin $\mathrm{C}$ to $2 \mathrm{mg} \mathrm{ml}^{-1}$. The selection and identification of lysogens was carried out as described in Silhavy et al. (1984). Briefly, a high-titre lysate of $\lambda$ GC101 was applied to a lawn of E. coli MC4100 and after overnight growth cells were purified from turbid plaques and their immunity checked by testing their ability to grow through phage streaks of different immunities including $\lambda$ imm21, $\lambda$ imm434 and $\lambda$ vir. Approximately 10 independent lysogens were then grown and assayed for $\beta$-galactosidase expression to screen single from multiple lysogens. In each $\lambda$ GC101 lysogen the $c y d A B$ genes were intact, as the lac $Z$ fusions were stably integrated into the $\lambda$ attachment site on the chromosome. P1vir transduction was carried out as described by Silhavy et al. (1984).

Spectrophotometry. Reduced-minus-oxidized difference spectra of membranes, resuspended in $50 \mathrm{mM}$ potassium phosphate buffer, were obtained as described previously (Cunningham \& Williams, 1995), using a Shimadzu MPS2000 spectrophotometer, reducing and oxidizing samples with sodium dithionite and ammonium persulphate, respectively. The concentration of cytochrome $d$ was determined using a millimolar absorption coefficient of 18.5 and a wavelength pair of $630-650 \mathrm{~nm}$. Protein was quantified by the method of Markwell et al. (1978).

Analysis of in vivo plasmid supercoiling. To determine the level of in vivo plasmid supercoiling, topoisomers were separated in $1 \%$ agarose gels containing $25 \mu \mathrm{g}$ chloroquine $\mathrm{ml}^{-1}$ (Ni Bhriain et al., 1989). The mobility of the different topoisomers varies depending on the chloroquine concentration and at $25 \mu \mathrm{g} \mathrm{ml}^{-1}$ the more relaxed topoisomers migrate fastest. Electrophoresis was carried out in a coldroom at constant voltage of $3 \mathrm{~V} \mathrm{~cm}^{-1}$ for $20 \mathrm{~h}$ with recirculation of the running buffer. The buffer contained $90 \mathrm{mM}$ Tris (pH 8.3), $90 \mathrm{mM}$ borate, $10 \mathrm{mM}$ EDTA and chloroquine at the same concentration as in the gel. Chloroquine was washed from the gel by soaking in distilled water for at least $4 \mathrm{~h}$ before staining with ethidium bromide $\left(5 \mu \mathrm{g} \mathrm{ml} \mathrm{m}^{-1}\right)$.

$\boldsymbol{\beta}$-Galactosidase assays. $\beta$-Galactosidase activity was assayed in cells grown in MMA with either glucose or lactate as carbon source as described previously (Georgiou et al., 1988). $\beta$ Galactosidase values represent the mean of three experiments with a variation of less than $10 \%$.

\section{RESULTS}

\section{Cytochrome $b d$ regulation in a $\Delta \operatorname{arcA} \Delta f n r$ mutant}

There have been a number of reports of the effects of mutation of $\operatorname{arc} A$ and $f n r$ on $c y d A B$ expression (Cotter et al., 1990, 1997; Iuchi et al., 1990, Cotter \& Gunsalus, 1992). We looked at this again here, but additionally 
Table 1. E. coli $\mathrm{K}-12$ strains

\begin{tabular}{|c|c|c|}
\hline Strain & Relevant characteristic(s) & Source or reference \\
\hline MC4100 & $\begin{array}{l}\mathrm{F}^{-} \text {araD139 } \Delta(\operatorname{argF}-l a c) U 169 \text { flbB5301 relA1 rpsL150 deoC1, } \\
\text { ptsF25 rbsR }\end{array}$ & Silhavy et al. (1984) \\
\hline JRG1728 & $\begin{array}{l}\text { lacX74 galU galK rpsL } \Delta(\text { ara-leu }) \\
\quad \Delta\left(\text { tyrR-fnr-rac-try) } z d d-230:: \operatorname{Tn} 9, \mathrm{Cm}^{\mathrm{R}}\right.\end{array}$ & J. R. Guest, University of Sheffield, UK \\
\hline PC35 & $\mathrm{MC} 4100 \Delta \operatorname{arcA}, \mathrm{Km}^{\mathrm{R}}$ & $\begin{array}{l}\mathrm{Km}^{\mathrm{R}} \text { results from the kanamycin-resistance gene from } \\
\text { pUC-4K (Pharmacia), inserted into } \operatorname{arcA} \text { (Cotter \& } \\
\text { Gunsalus, 1992) }\end{array}$ \\
\hline CSCG 6601 & $\mathrm{~F}^{-} z e g-298:: \operatorname{Tn} 10$ gyrA261 $\lambda^{-}, \mathrm{Tc}^{\mathrm{R}} \mathrm{Nal}^{\mathrm{R}}$ & B. Bachmann, E. coli Genetic Stock Center \\
\hline HW434 & HW456 zeg-298::Tn10 gyrA261 $\Phi\left(c y d A^{\prime}-l a c Z\right), \mathrm{Tc}^{\mathrm{R}} \mathrm{Nal}^{\mathrm{R}} \mathrm{Ap}^{\mathrm{R}}$ & $\begin{array}{l}\text { P1.CSCG } 6601 \times \mathrm{HW} 456 \text {, selecting for } \mathrm{Tc}^{\mathrm{R}} \text { and } \\
\text { screening for } \mathrm{Nal}^{\mathrm{R}}\end{array}$ \\
\hline HW443 & MC4100 $\Delta(t y r R-f n r-r a c-t r y) z d d-230:: \operatorname{Tn} 9, \mathrm{Cm}^{\mathrm{R}}$ & P1.JRG1728 $\times$ MC4100, selecting for $\mathrm{Cm}^{\mathrm{R}}$ \\
\hline HW445 & MC4100 $\Delta \operatorname{arcA} \Delta(t y r R-f n r-r a c-t r y) z d d-230:: \operatorname{Tn} 9, \mathrm{Cm}^{\mathrm{R}} \mathrm{Km}^{\mathrm{R}}$ & P1.PC35 $\times$ HW443, selecting for $\mathrm{Km}^{\mathrm{R}}$ \\
\hline HW447 & HW445 zeg-298:: $\operatorname{Tn} 10$ gyrA261, $\mathrm{Cm}^{\mathrm{R}} \mathrm{Km}^{\mathrm{R}} \mathrm{Tc}^{\mathrm{R}} \mathrm{Nal}^{\mathrm{R}}$ & $\begin{array}{l}\text { P1.HW } 434 \times \mathrm{HW} 445 \text {, selecting for } \mathrm{Tc}^{\mathrm{R}} \text { and screening } \\
\text { for } \mathrm{Nal}^{\mathrm{R}}\end{array}$ \\
\hline HW456 & MC4100 $\Phi\left(c y d A^{\prime}-l a c Z\right), \mathrm{Ap}^{\mathrm{R}}$ & $\lambda \mathrm{GC101} \times \mathrm{MC} 4100$, selecting for $\mathrm{Ap}^{\mathrm{R}}$ \\
\hline HW457 & HW445 $\Phi\left(c y d A^{\prime}-l a c Z\right), \mathrm{Ap}^{\mathrm{R}} \mathrm{Cm}^{\mathrm{R}} \mathrm{Km}^{\mathrm{R}}$ & $\lambda \mathrm{GC101} \times \mathrm{HW} 445$, selecting for $\mathrm{Ap}^{\mathrm{R}}$ \\
\hline HW461 & $\mathrm{HW} 447 \Phi\left(c y d A^{\prime}-l a c Z\right), \mathrm{Cm}^{\mathrm{R}} \mathrm{Km}^{\mathrm{R}} \mathrm{Tc}^{\mathrm{R}} \mathrm{Nal}^{\mathrm{R}} \mathrm{Ap}^{\mathrm{R}}$ & $\lambda \mathrm{GC} 101 \times \mathrm{HW} 447$ selecting for $\mathrm{Ap}^{\mathrm{R}}$ \\
\hline
\end{tabular}

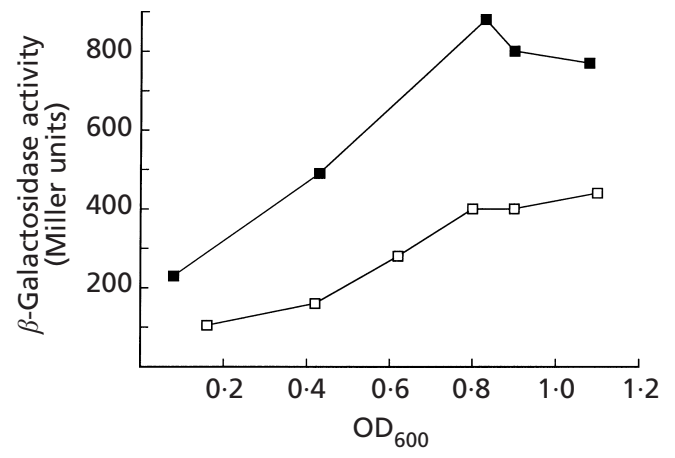

Fig. 1. Effect of deletion of $\operatorname{arc} A$ and $f n r$ on $c y d A$ expression. $E$.

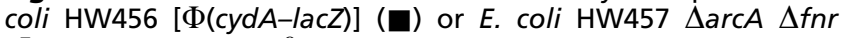
$[\Phi(c y d A-l a c Z)](\square) . \beta$-Galactosidase activity was assayed as a function of growth in lactate-containing MMA.

followed $c y d A-l a c Z$ expression throughout the growth curve and looked at final cytochrome $b d$ levels in membranes using difference spectrophotometry. During aerobic growth in lactate minimal medium, cydA-lacZ expression increased during exponential growth to a maximum as the culture approached stationary phase (Fig. 1). A similar pattern of expression was seen in HW457 $\Delta a r c A \Delta f n r$ except that the final expression levels were about half those found in HW456. In both strains expression was induced about fourfold during growth.

We determined whether the level of spectrally detectable cytochrome bd in HW456 and HW457 reflected the pattern of $c y d A-l a c Z$ expression observed. Membranes from both strains had the characteristic signals of cytochrome $b d$ in reduced-minus-oxidized spectra (data not shown): a weak maximum at $595 \mathrm{~nm}$ due to cytochrome b595, a prominent peak at $628 \mathrm{~nm}$ due to reduced cytochrome $d$ and a trough at $650 \mathrm{~nm}$ resulting from the oxygenated form of cytochrome $d$ (the dominant species in the 'oxidized' reference cuvette (Miller \& Gennis, 1983; Poole et al., 1983). Quantification of cytochrome $d$ levels showed that there was a $35 \%$ reduction of the levels of cytochrome $d$ in HW457 $\triangle$ arcA $\Delta f n r$ compared to HW456 (Fig. 2), in contrast to a $60 \%$ reduction in $\beta$-galactosidase activity between these strains at the same point in the growth curve. This indicates that while mutation of the regulatory genes $\operatorname{arc} A$ and $f n r$ leads to a reduction in cytochrome $b d$ levels, a significant fraction of the wild-type activity remains.

\section{DNA gyrase inhibitors affect cydAB expression}

The level of DNA supercoiling in vivo can be perturbed by using specific inhibitors of DNA gyrase. To determine whether DNA supercoiling has a role in the regulation of $c y d A B$ expression, the effect of the DNA gyrase inhibitors novobiocin and nalidixic acid on $c y d A-l a c Z$ expression were investigated. Concentrations of novobiocin up to $50 \mu \mathrm{g} \mathrm{ml}^{-1}$ had no effect and up to $150 \mu \mathrm{g} \mathrm{ml}^{-1}$ only a marginal effect on the growth rate of HW456 (data not shown). However, increasing concentrations of novobiocin led to a progressive reduction in cydA-lacZ expression in samples taken from lateexponential-phase cultures (Fig. 3a). Concentrations of nalidixic acid up to $2.5 \mu \mathrm{g} \mathrm{ml}^{-1}$ did not alter the growth rate and also reduced the expression of $c y d A-l a c Z$ in late-exponential-phase cultures in a concentration-dependent manner (Fig. 3b). Both novobiocin and nalidixic acid had a substantial effect on the pattern of $c y d A-l a c Z$ expression throughout the growth cycle (Fig. 4). Novobiocin at $50 \mu \mathrm{g} \mathrm{ml}^{-1}$ delayed the normal induction of cydA-lacZ expression (Fig. 4). At $150 \mu \mathrm{g}$ novobiocin $\mathrm{ml}^{-1}$, expression remained at a low basal level 


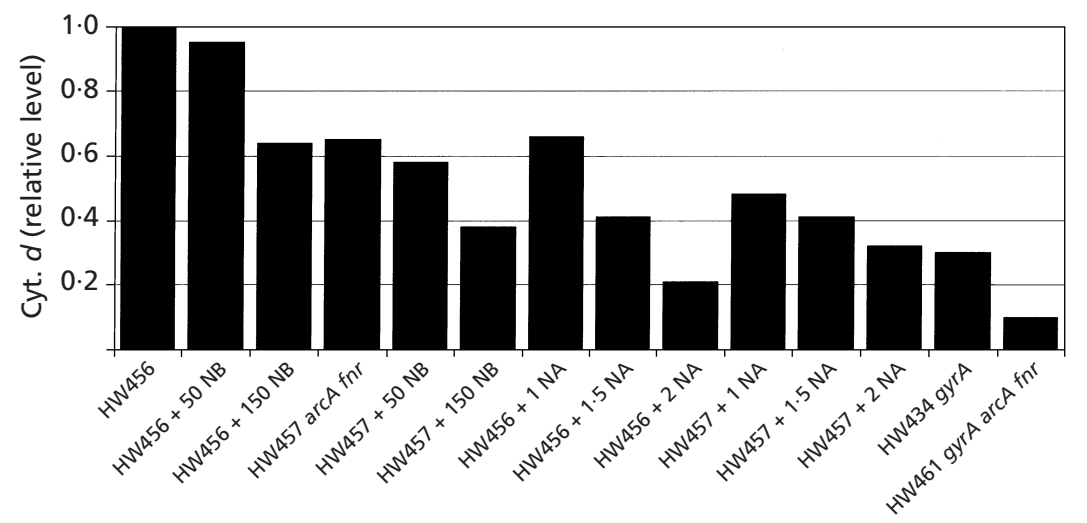

Fig. 2. Spectral levels of cytochrome $d$, determined in membrane preparations from cells grown in lactate-containing MMA to an $\mathrm{OD}_{600}$ of 0.8 . Reduced-minus-oxidized difference spectra were recorded and the levels of cytochrome $d$ quantified from $\Delta A_{628-650}$ and an absorption coefficient of $18.5 \mathrm{mM} \mathrm{cm}^{-1}$ as described in Methods. NA is nalidixic acid and NB is novobiocin and the indicated quantities of both are in units of $\mu \mathrm{g} \mathrm{ml}^{-1}$.
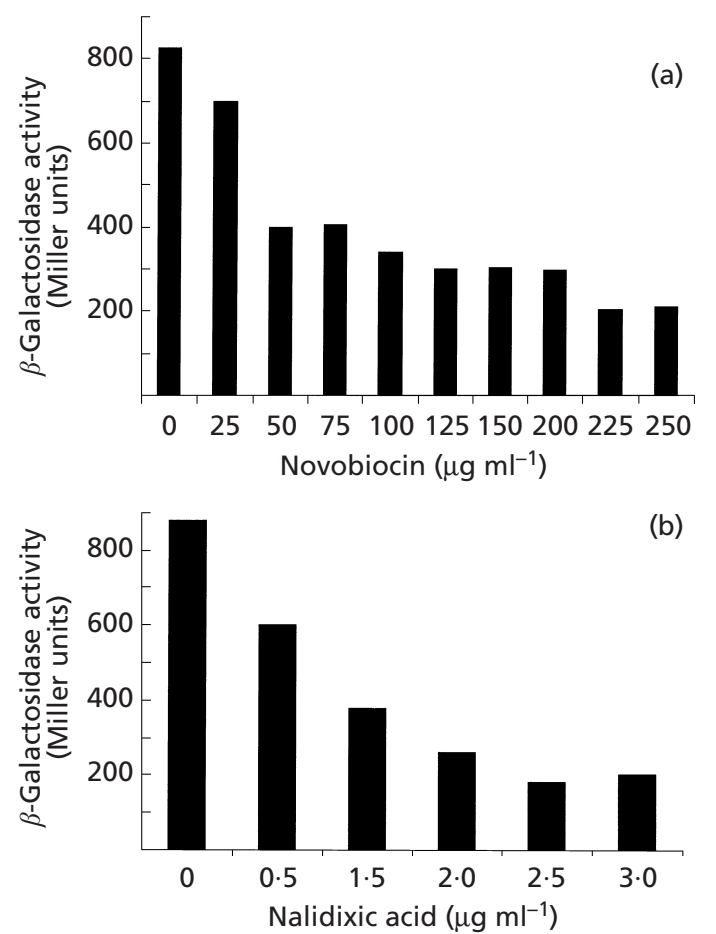

Fig. 3. Effect of DNA gyrase inhibitors on $c y d A$ expression. $E$. coli HW456 [Ф(cydA-lacZ)] was grown in lactate-containing MMA to an $\mathrm{OD}_{600}$ of 0.8 in the presence of the indicated concentrations of novobiocin (a) or nalidixic acid (b) and $\beta$ galactosidase activity assayed.

throughout the experiment. In the presence of $1.5 \mu \mathrm{g}$ nalidixic acid $\mathrm{ml}^{-1}$ the induction of $c y d A B$ expression was reduced compared to that in HW456, while with $2.5 \mu \mathrm{g}$ nalidixic acid $\mathrm{ml}^{-1}$ induction from the basal level was completely abolished. Under the conditions used for the $c y d A B$ expression experiments, we confirmed that the concentrations of novobiocin and nalidixic acid used affected the in vivo supercoiling levels of the plasmid pBR322. pBR322 DNA isolated from novobiocin and nalidixic acid treated cells, when examined on chloroquine-agarose gels, showed topoisomers that migrated more rapidly than plasmid from untreated
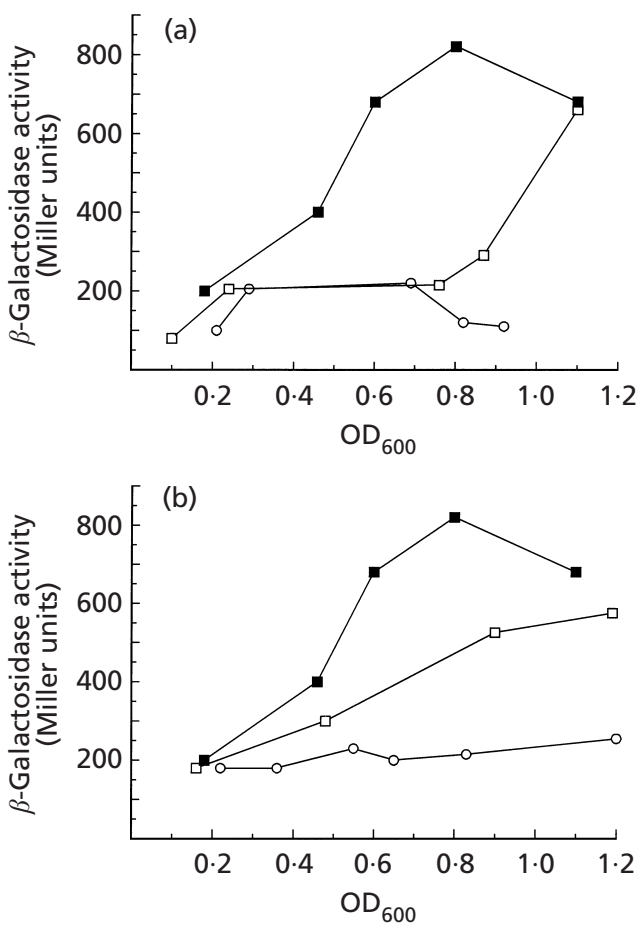

Fig. 4. Effect of DNA gyrase inhibitors on $c y d A$ expression throughout the growth cycle. (a) HW456 (ם); HW456+50 $\mu \mathrm{g}$ novobiocin $\mathrm{ml}^{-1}(\square)$; HW456+150 $\mathrm{gg}$ novobiocin $\mathrm{ml}^{-1}$ (O). (b) HW456 (口); HW456+1.5 $\mathrm{g} \mathrm{ml}^{-1}$ nalidixic acid ( $\square$ ); HW456+2.5 $\mu \mathrm{g} \mathrm{ml}^{-1}$ nalidixic acid (O). $\beta$-Galactosidase activity was assayed as a function of growth in lactate-containing MMA.

cells, consistent with previous published results (Dorman et al., 1988) (data not shown). This indicated the plasmid DNA to be more relaxed, consistent with less negatively supercoiled DNA, as would be expected with inhibition of DNA gyrase. These data are consistent with a correlation between the levels of in vivo supercoiling and $c y d A B$ expression. The levels of cytochrome $d$ in late-exponential-phase cultures treated with novobiocin or nalidixic acid are shown in Fig. 2: $50 \mu \mathrm{g}$ novobiocin $\mathrm{ml}^{-1}$ had no effect on the amount of spectrally detectable cytochrome $d$ in membranes, while 

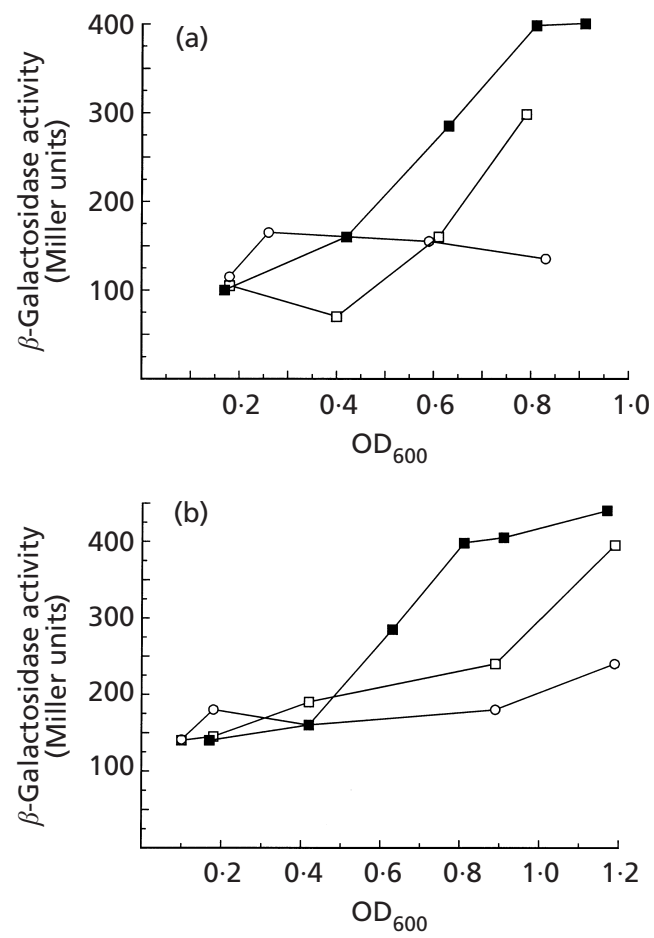

Fig. 5. Effect of DNA gyrase inhibitors on $c y d A$ expression in a $\triangle \operatorname{arcA} \Delta$ fnr background. (a) HW457 $\triangle \operatorname{arcA} \Delta$ fnr ( $\mathbf{\square}$ ); HW457 $\Delta a r c A \quad \Delta f n r+50 \mu \mathrm{g}$ novobiocin $\mathrm{ml}^{-1}(\square) ; \mathrm{HW} 457 \quad \Delta \operatorname{arcA}$ $\Delta$ fnr $+150 \mu \mathrm{g}$ novobiocin $\mathrm{ml}^{-1}$ (O). (b) HW457 $\Delta$ arcA $\Delta$ fnr (ם); HW457 $\Delta$ arcA $\Delta f n r+1.5 \mu \mathrm{g}$ nalidixic acid $\mathrm{ml}^{-1}(\square)$; HW457 $\Delta \operatorname{arc} A \Delta f n r+2.5 \mu \mathrm{g}$ nalidixic acid $\mathrm{ml}^{-1}(\bigcirc)$. $\quad \beta$-Galactosidase activity was assayed as a function of growth in lactatecontaining MMA.

$150 \mu \mathrm{g} \mathrm{ml}^{-1}$ reduced levels to $60 \%$ of those in the untreated cells. Increasing nalidixic acid concentrations led to a progressive decrease in the levels of cytochrome $d$, to $20 \%$ of the untreated levels in membranes from cultures treated with $2 \mu \mathrm{g}$ nalidixic acid $\mathrm{ml}^{-1}$.

\section{The effect of DNA gyrase inhibitors on $c y d A B$ expression is independent of the ArcAB regulon and Fnr}

To determine whether novobiocin and nalidixic acid decrease $c y d A B$ expression via direct or indirect effects on either the ArcAB regulon or Fnr, we determined whether these DNA gyrase inhibitors modified $c y d A B$ expression in a $\Delta a r c A \Delta f n r$ background. The data in Fig. 5 show that both novobiocin and nalidixic acid reduced cydA-lacZ expression in the $\Delta \operatorname{arc} A \Delta f n r$ double mutant HW457. With $50 \mu \mathrm{g}$ novobiocin $\mathrm{ml}^{-1}$, the reduced level of induction observed in the $\Delta a r c A \Delta f n r$ background was delayed, while induction was abolished with $150 \mu \mathrm{g} \mathrm{ml}^{-1}$. Similarly, nalidixic acid treatment led to a concentration-dependent reduction in cydA-lacZ expression in a $\Delta \operatorname{arc} A \Delta f n r$ background, with $\beta$-galactosidase levels remaining at a basal level of around 150 units throughout growth. Novobiocin at $150 \mu \mathrm{g} \mathrm{ml} l^{-1}$, and all concentrations of nalidixic acid

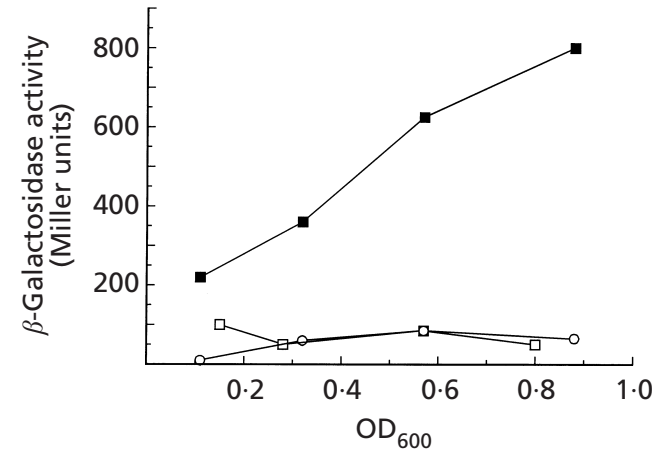

Fig. 6. Effect of gyrA mutation on cydA expression. $\mathbf{}, \mathrm{HW} 456$; $\square$, HW434 gyrA261; O, HW461 $\Delta$ arcA $\Delta$ fnr gyrA261. $\beta$ Galactosidase activity was assayed as a function of growth in lactate-containing MMA.

tested, significantly reduced cytochrome $d$ levels in membranes (Fig. 2). In conclusion, these data suggest that any effect on $c y d A B$ expression through modifying DNA supercoiling is not a result of indirect effects on the expression of or binding of ArcA or Fnr to the $c y d A B$ promoters.

\section{A gyrA mutation affects cytochrome bd expression}

Since gyrase inhibitors are capable of reducing cytochrome $b d$ expression, we further examined the effect of a gyrA mutation on $c y d A-l a c Z$ expression. HW434 gyrA261 showed a dramatic reduction in cydA-lacZ expression throughout growth compared to its isogenic parent, HW456 (Fig. 6). No induction of expression was observed above the basal level present at the start of exponential growth. Transduction of the gyrA261 mutation into a $\Delta \operatorname{arc} A \Delta f n r$ background, to construct HW461, led to a similarly severe repression of $c y d A-$ lacZ expression. Spectral analysis supported the gene fusion data, in that cytochrome $d$ spectral signals were markedly reduced in gyrA261 backgrounds (Fig. 2). Analysis of the distribution of topoisomers of plasmid DNA isolated from HW456 and HW434 backgrounds confirmed that the plasmid DNA was indeed more relaxed in the gyrA261 background (data not shown), which is indicative of a reduction in negative supercoiling leading to a reduction in cytochrome $b d$ expression.

\section{Effect of mutation of gyrA on the anaerobic expression of cytochrome bd}

Finally, we examined the effect of a gyrA mutation on the anaerobic expression of cytochrome $b d$. Negative DNA supercoiling is increased under anaerobic compared to aerobic conditions (Dorman et al., 1988). Therefore, if our model is correct, and this increase in negative supercoiling is in part responsible for the induction of $c y d A B$ under anaerobic conditions, then we would predict that anaerobic induction of $c y d A B$ would be abolished in a gyr $A$ background. For this experiment 

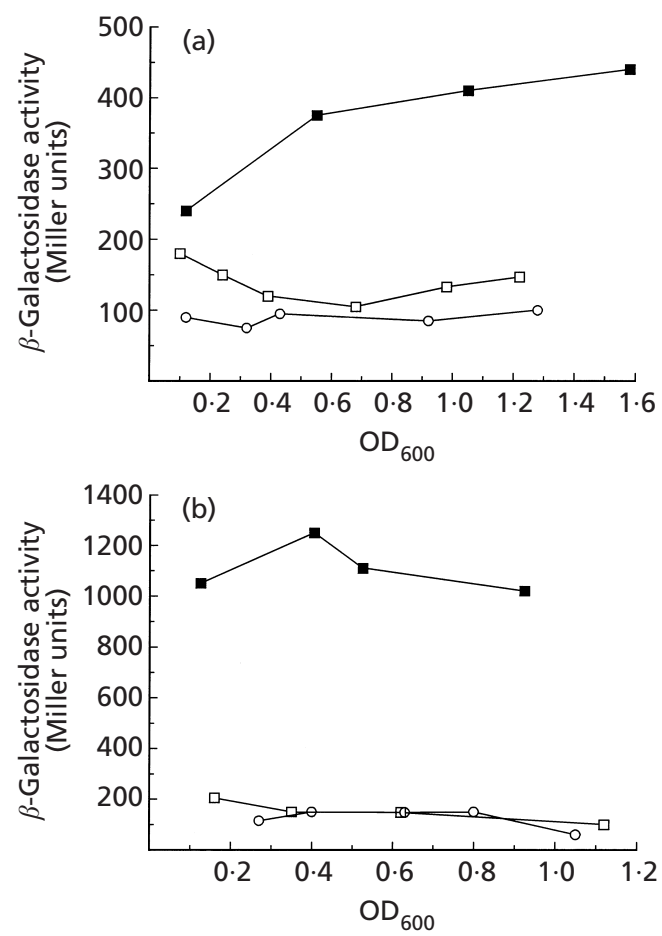

Fig. 7. Effect of gyrA mutation on cydA expression during (a) aerobic and (b) anaerobic growth in MMA medium with glucose as the carbon source. $\square, \mathrm{HW} 456 ; \square, \mathrm{HW} 434$ gyrA261; O, HW461 $\Delta$ arcA $\Delta$ fnr gyrA261. $\beta$-Galactosidase activity was assayed as a function of growth.

we grew cultures with glucose as the fermentable carbon source, and so we first confirmed that gyrA261 abolishes induction of $c y d A B$ during aerobic growth on glucose. This indeed was the case in both gyrA261 and gyrA261 $\Delta \operatorname{arc} A \Delta f n r$ backgrounds (Fig. 7a). In addition, Fig. 7(b) clearly shows that anaerobic induction of $c y d A-l a c Z$ is abolished in gyrA261 backgrounds.

\section{DISCUSSION}

It is well established that the $c y d A B$ operon is under the control of the Arc regulon and Fnr (Lynch \& Lin, 1996). However, it is clear that there is a further level of regulation that has not been elucidated. Evidence for this comes from the finding that strains deleted for $\operatorname{arc} A$ and $f n r$ still show significant induction of expression under anaerobic conditions (Lynch \& Lin, 1996; Cotter et al., 1997; this study, Fig. 7), and during entry into stationary phase, when oxygen levels will be depleted (Fig. 1). However, no further transcriptional regulators have been found to have a role in cytochrome $b d$ regulation. It is well established that many prokaryotic genes have their transcription modified by the levels of negative DNA supercoiling in the cell (Schrum \& Hassan, 1992; Drlica, 1992; Dimri \& Das, 1988; Ni Bhriain et al., 1989; Dorman, 1995; Dorman et al., 1988; Graeme-Cook et al., 1989, Grau et al., 1994; Karem \& Foster, 1993; O’Byrne et al., 1992; Sun \& Fuchs, 1994). Furthermore, there is an increase in the levels of DNA supercoiling following a shift from highto low-oxygen conditions (Dorman et al., 1988). Therefore, we hypothesized that the increase in DNA supercoiling that occurs upon a shift to low-oxygen conditions might have a role in inducing $c y d A B$ expression. In support of this we report several lines of evidence. Firstly, expression of $c y d A B$ is sensitive to two inhibitors of DNA gyrase, the enzyme responsible for introducing negative supercoiling into DNA, that differ in their mode of action. Secondly, expression is altered in mutants with lesions in the gyrA gene, which encodes DNA gyrase. DNA supercoiling is modulated by the actions of topoisomerase I, which causes DNA relaxation by making single-strand breaks in the DNA, and DNA gyrase, which is responsible for both relaxation and increasing negative supercoiling by an ATP-dependent mechanism (Drlica \& Coughlin, 1989). The activity of DNA gyrase is inhibited by nalidixic acid, which affects the A subunit by trapping the gyrase-DNA complex (Drlica, 1992), and by novobiocin, which blocks ATP hydrolysis (Fisher et al., 1992). We report here that both novobiocin and nalidixic acid decreased expression of a $c y d A-l a c Z$ fusion in a concentrationdependent manner and at concentrations that reduced the negative supercoiling of a reporter plasmid.

Besides gyrase inhibitors, the level of DNA supercoiling can be perturbed by mutation of the gyrA gene. In an isogenic $c y d A-l a c Z$ fusion strain carrying a $g y r A$ mutation there was a marked reduction of cydA-lacZ expression throughout the growth cycle. The levels of spectrally detectable cytochrome $b d$ broadly followed cydA-lac $Z$ expression levels, indicating that changes in supercoiling alter the effective cytochrome $b d$ oxidase levels in the cell. We considered the possibility that changes in supercoiling might be affecting $c y d A B$ expression by altering the ability of the $c y d A B$ promoter to respond to regulatory proteins ArcA and Fnr, or by altering the expression of $\operatorname{arc} A$, $\operatorname{arcB}$ or $f n r$. To investigate this possibility the effects of DNA gyrase inhibitors and a gyrA mutant on $c y d A-l a c Z$ expression were investigated in a $\Delta \operatorname{arc} A \Delta f n r$ background. However, it is clear that both gyrase inhibitors and gyrA mutation reduce $c y d A B$ expression in a strain background deleted of $\operatorname{arcA}$ and $\mathrm{fnr}$ (Figs 5 and 6). These data do not prove but are consistent with a role for DNA supercoiling in the regulation of $c y d A B$ operon expression. As our experiments involve artificial perturbation of supercoiling levels they cannot provide definitive evidence that DNA supercoiling regulates cytochrome $b d$, while DNA supercoiling measured using reporter plasmids may not give a perfectly accurate picture of the levels of chromosomal supercoiling. However, the fact that we obtained similar results with two different gyrase inhibitors and with a gyrA mutant, together with the previous demonstrations that changes in oxygen availability perturb cellular supercoiling levels, gives us confidence in concluding that DNA supercoiling has a role in regulating the levels of cytochrome bd in E. coli.

Entry into stationary phase through carbon starvation 
alters the level of DNA supercoiling (Dorman et al., 1988; Balke \& Gralla, 1987). It is known that cytochrome $b d$ is required for effective exit from stationary phase (Siegele \& Kolter, 1993, Siegele et al., 1996; Goldman et al., 1996). Therefore, perhaps control of $c y d A B$ expression by changes in DNA supercoiling provides a general way of upregulating $c y d A B$ levels in response to environmental stresses that might lead to cessation of growth. E. coli has a branched aerobic respiratory chain; the relatively low oxygen affinity but energetically efficient oxidase, cytochrome $b o^{\prime}$, is preferred under high-oxygen conditions. It would be interesting to examine if it is also regulated by DNA supercoiling perturbations and if so whether they affect it in the opposite direction to $c y d A B$ in order to achieve co-ordinate regulation of these oxidases.

\section{ACKNOWLEDGEMENTS}

This work was funded by the BBSRC. We are very grateful to Barbara Bachmann, John Guest and Robert Gunsalus for strains and to Robert Gennis for $\lambda \mathrm{GC} 101$.

\section{REFERENCES}

Atlung, T. \& Brøndsted, L. (1994). Role of the transcriptional activator AppY in regulation of the cyx appA operon of Escherichia coli by anaerobiosis, phosphate starvation, and growth phase. J Bacteriol 176, 5414-5422.

Balke, V. L. \& Gralla, J. D. (1987). Changes in the linking number of supercoiled DNA accompany growth transitions in Escherichia coli. J Bacteriol 169, 4499-4506.

Cotter, P. A. \& Gunsalus, R. P. (1992). Contribution of the $f n r$ and $\operatorname{arc} A$ gene products in coordinate regulation of cytochrome $o$ and $d$ oxidases (cyoABCDE and cydAB genes) in Escherichia coli. FEMS Microbiol Lett 91, 31-36.

Cotter, P. A., Chepuri, V., Gennis, R. B. \& Gunsalus, R. P. (1990). Cytochrome o (cyoABCDE) and $d(c y d A B)$ oxidase gene expression in Escherchia coli is regulated by oxygen, $\mathrm{pH}$ and the $\mathrm{fnr}$ gene product. J Bacteriol 172, 6333-6338.

Cotter, P. A., Melville, S. B., Albrecht, J. A. \& Gunsalus, R. P. (1997). Aerobic regulation of cytochrome $d$ oxidase (cydAB) operon expression in Escherichia coli: roles of Fnr and ArcA in repression and activation. Mol Microbiol 25, 605-615.

Cunningham, L. \& Williams, H. D. (1995). Isolation and characterisation of mutants defective in the cyanide insensitive respiratory pathway of Pseudomonas aeruginosa. J Bacteriol 177, 432-438.

Dassa, E., Fsihi, H., March, C., Dion, M., Kieffer-Bontemps, M. \& Boquet, P. L. (1991). A new oxygen-regulated operon in Escherichia coli comprises the genes for a putative third cytochrome oxidase and for $\mathrm{pH} 2.5$ acid phosphatase (appA). Mol Gen Genet 229, 341-352.

Dimri, G. P. \& Das, H. K. (1988). Transcriptional regulation of nitrogen fixation genes by DNA supercoiling. Mol Gen Genet 212, 360-363.

D'Mello, R., Hill, S. \& Poole, R. K. (1996). The cytochrome bd quinol oxidase in Escherichia coli has an extremely high apparent affinity for oxygen and two oxygen-binding haems: implications for regulation of activity in vivo by substrate (oxygen) inhibition. Microbiology 142, 755-763.

Dorman, C. J. (1995). DNA topology and the global control of bacterial gene expression: implications for the regulation of virulence gene expression in pathogenic bacteria. Microbiology 141, 1271-1280.

Dorman, C. J., Barr, G. C., Ni Bhriain, N. \& Higgins, C. F. (1988). DNA supercoiling and the anaerobic and growth phase regulation of tonB gene expression. J Bacteriol 179, 2816-2826.

Drlica, K. (1992). Control of bacterial DNA supercoiling. Mol Microbiol 6, 425-433.

Drlica, K. \& Coughlin, S. (1989). Inhibitors of DNA gyrase. Pharmacol Ther 44, 107-121.

Fisher, L. M., Austin, C. A., Hopewell, R., Margerrison, E. E. C., Oram, M., Patel, S., Plummer, K., Sng, J.-H. \& Sreedharan, S. (1992). DNA supercoiling and relaxation by ATP-dependent DNA topoisomerases. Philos Trans R Soc Lond Ser B Biol Sci 336, 83-91.

García-Horsman, J. A., Barquera, B., Rumbley, J., Ma, J. \& Gennis, R. B. (1994). The superfamily of haem-copper respiratory oxidases. J Bacteriol 176, 5587-5600.

Gennis, R. B. \& Stewart, V. (1996). Respiration. In Escherichia coli and Salmonella typhimurium: Cellular and Molecular Biology, 2nd edn, pp. 217-261. Edited by F. C. Neidhardt and others. Washington, DC: American Society for Microbiology.

Georgiou, C. D., Dueweke, T. J. \& Gennis, R. B. (1988). Regulation of expression of cytochrome $d$ of Escherichia coli is transcriptional. J Bacteriol 170, 961-966.

Goldman, B. S., Gabbert, K. K. \& Kranz, R. G. (1996). The temperature-sensitive growth and survival phenotypes of Escherichia coli $c y d D C$ and $c y d A B$ strains are due to deficiencies in cytochrome $b d$ and are corrected by exogenous catalase and reducing agents J Bacteriol 178, 6348-6351.

Graeme-Cook, K. A., May, G., Bremer, E. \& Higgins, C. F. (1989). Osmotic regulation of porin expression: a role for DNA supercoiling. Mol Microbiol 3, 1287-1294.

Grau, R., Gardiol, D., Gilkin, G. C. \& di Mendoza, D. (1994). DNA supercoiling and thermal regulation of unsaturated fatty acid synthesis in Bacillus subtilis. Mol Microbiol 11, 933-941.

Green, N. G., Fang, H., Lin, R.-J., Newton, G., Mather, M., Georgiou, C. \& Gennis, R. B. (1988). The nucleotide sequence of the cyd locus encoding the two subunits of the cytochrome $d$ terminal oxidase complex of Escherichia coli. J Biol Chem 263, 13138-13143.

Hill, J. J., Alben, J. O. \& Gennis, R. B. (1993). Spectroscopic evidence for a haem-haem binuclear center in the cytochrome $b d$ ubiquinol oxidase from Escherichia coli. Proc Natl Acad Sci US A 90, 5863-5867.

luchi, S., Chepuri, V., Fu, H.-A., Gennis, R. B. \& Lin, E. C. C. (1990). Requirement for terminal cytochromes in generation of the aerobic signal for the arc regulatory system in Escherichia coli: study using deletions and lac fusions of cyo and cyd. J Bacteriol 172, 6020-6025.

Junemann, S. (1997). Cytochrome $b d$ terminal oxidase. Biochim Biophys Acta 132, 107-127.

Karem, K. \& Foster, J. W. (1993). The influence of DNA topology on the environmental regulation of a $\mathrm{pH}$ regulated locus in Salmonella typhimurium. Mol Microbiol 10, 75-86.

Lorence, R. M., Carter, K., Green, G. N. \& Gennis, R. B. (1987). Cytochrome $b-558$ monitors the steady-state redox state of the ubiquinone pool in the aerobic respiratory chain of Escherichia coli. J Biol Chem 262, 10532-10536.

Lynch, A. S. \& Lin, E. C. C. (1996). Responses to molecular oxygen. In Escherichia coli and Salmonella typhimurium: Cellular and Molecular Biology, 2nd edn, pp. 1526-1538. Edited by F. C. 
Neidhardt and others. Washington, DC: American Society for Microbiology.

Markwell, M. A. K., Haas, S. M., Bieber, L. L. \& Tolbert, N. E. (1978). A modification of the Lowry procedure to simplify protein determination in membrane and lipoprotein samples. Anal Biochem 87, 206-210.

Miller, J. (1972). Experiments in Molecular Genetics. Cold Spring Harbor, NY : Cold Spring Harbor Laboratory.

Miller, M. J. \& Gennis, R. B. (1983). The purification and characterisation of the cytochrome $d$ terminal oxidase complex of the Escherichia coli aerobic respiratory chain. J Biol Chem 258, 9159-9165.

Ni Bhriain, N., Dorman, C. J. \& Higgins, C. F. (1989). An overlap between osmotic and anaerobic stress responses: a potential role for DNA supercoiling in the coordinate regulation of gene expression. Mol Microbiol 3, 933-942.

O'Byrne, C. P., Ni Bhriain, N. \& Dorman, C. J. (1992). The DNA sensitive supercoiling sensitive expression of the Salmonella typhimurium his operon requires the his attenuator and is modulated by anaerobiosis and by osmolarity. Mol Microbiol 6, 2467-2476.

Poole, R. K. \& Ingledew, W. J. (1987). Pathways of electrons to oxygen. In Escherichia coli and Salmonella typhimurium: Cellular and Molecular Biology, pp. 170-200. Edited by F. C. Neidhardt and others. Washington, DC: American Society for Microbiology.

Poole, R. K., Kumar, C., Salmon, I. \& Chance, B. (1983). The $650 \mathrm{~nm}$ chromophore in Escherichia coli is an oxy-compound or oxygenated compound, not the oxidized form of cytochrome oxidase $d$ - an hypothesis. J Gen Microbiol 129, 1335-1344.

Poole, R. K., Salmon, I. \& Chance, B. (1994). The high-spin cytochrome $o^{\prime}$ component of the cytochrome bo-type quinol oxidase in membranes from Escherichia coli: formation of the primary oxygenated species at low temperatures is characterized by a slow 'on' rate and low dissociation constant. Microbiology 140, 1027-1034.
Pudek, M. R. \& Bragg, P. D. (1974). Inhibition by cyanide of the respiratory chain oxidases of Escherichia coli. Arch Biochem Biophys 164, 682-693.

Rice, C. W. \& Hempfling, W. P. (1978). Oxygen-limited continuous culture and respiratory energy conservation in Escherichia coli. J Bacteriol 134, 115-124.

Rothery, R. \& Ingledew, W. J. (1989). The cytochromes of anaerobically grown Escherichia coli. An electron paramagnetic study of the cytochrome $b d$ complex in situ. Biochem J 262, 437-443.

Schrum, L. W. \& Hassan, H. M. (1992). Transcriptional regulation of Mn-superoxide dismutase gene $(\operatorname{sod} A)$ of Escherichia coli is stimulated by DNA gyrase inhibitors. Arch Biochem Biophys 209, 185-192.

Siegele, D. A. \& Kolter, R. (1993). Isolation and characterization of an Escherichia coli mutant defective in resuming growth after starvation. Genes Dev 7, 2629-2640.

Siegele, D. A., Imlay, K. R. \& Imlay, J. A. (1996). The stationaryphase-exit defect of $c y d C(\operatorname{sur} B)$ mutants is due to the lack of a functional terminal cytochrome oxidase. I Bacteriol 178, 6091-6096.

Silhavy, T. J., Berman, M. L. \& Enquist, L. W. (1984). Experiments with Gene Fusions. Cold Spring Harbor, NY: Cold Spring Harbor Laboratory.

Sturr, M. G., Krulwich, T. A. \& Hicks, D. B. (1996). Purification of a cytochrome $b d$ terminal oxidase encoded by the Escherichia coli app locus from a $\Delta c y o \Delta c y d$ strain complemented by genes from Bacillus firmus OF4. J Bacteriol 176, 1742-1749.

Sun, L. \& Fuchs, J. A. (1994). Regulation of the Escherichia coli nrd operon: role of DNA supercoiling. J Bacteriol 176, 4617-4626.

Received 21 September 2000; revised 6 November 2000; accepted 13 November 2000. 